\title{
Peertechz
}

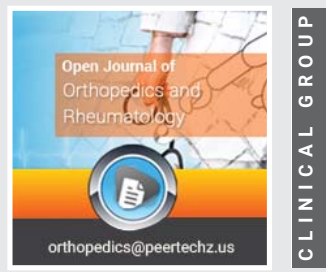

\section{Bisphosphonates promote healing of complicated stress fractures in the foot}

*Corresponding author: E Fink-Eriksen, MD, DMSc, Professor, Departments of Odontology, Oslo University Hospital Spesialistsenteret Pilestredet Park, Norway, E-mail: e.f.eriksen@medisin.uio.no

Keywords: Stress fracture; Bisphosphonates; Bone marrow edema; Bone marrow lesions

https://www.peertechzpublications.com

\section{E Fink-Eriksen ${ }^{1 *}$, T lanssen $^{2}$ and EE Husebye ${ }^{2}$}

\section{Check for updates}

${ }^{2}$ Departments of Orthopedic Surgery, Oslo University Hospital Spesialistsenteret Pilestredet Park, Norway

\begin{abstract}
Delayed healing of stress fractures constitutes a significant clinical problem causing pain and disability for the patients affected. The vast majority heal after immobilization of the extremity affected, but a certain small number of patients display delayed union despite standard treatment, resulting in prolonged disability and usually end up needing orthopedic procedures to get symptomatic relief. All stress fractures exhibit Bone Marrow Edema or Bone Marrow Lesions (BMLs) with and without fracture lines on MRI, and in cases of delayed union these lesions persist. Thus, it is conceivable that BML formation might contribute to non-union. Previous studies on transient osteoporosis and osteoarthritis have demonstrated that bisphosphonates can reduce BMLs. We therefore wanted to test, whether treatment with IV. Bisphosphonates could promote healing of such fractures. In this study we report our clinical experience and the results obtained after treating 8 patients exhibiting delayed healing an off label protocol using two Zoledronic acid infusions (given 3 months apart).
\end{abstract}

Seven female and one male patient (aged 30-72) were enrolled. All had signs of non-union for more than 12 months (defined as continued pain, disability and persistent BMLs on MRI). Pain was monitored using VAS (1-10) and MRI was performed in six of the patients at baseline, 3,6 and 12 months after the first infusion. All patients received $\mathrm{Ca}$ (0.5-1 g Ca per day) and vitamin D supplementation (800-1000 IE per day).

All patients experienced clinical healing with significant reduction of pain at the fracture site and improvement of ambulation within 1-3 months after the first infusion. 4 patients experienced further reducgtion of pain after the second infusion. At 6 months, ambulatory functions were completely restored in all patients and a highly significant reduction of VAS scores from an average of 7.3 before treatment to 1.1 at 6 months and 0,9 at 12 months (P<0,0001) could be demonstrated. The alleviation of pain was accompanied by reduction or total resolution of BMLs on MRI. Except for 2 cases of flu-like symptoms after the first infusion, no adverse effects were recorded.

In conclusion, In conclusion, 2 infusions of zoledronic acid (5 mg) given 3 months apart, may emerge as a possible treatment modality of stress fractures in the foot showing delayed union, and could potentially reduce the need for more extensive surgical intervention in such complicated cases. This small observational pilot study needs to be corroborated in a larger randomized, controlled trial.

\section{Introduction}

Stress fractures constitute a significant clinical problem and may affect individuals at all ages. They are a common cause of injury in runners and military recruits being associated with vigorous weight-bearing physical exercise. Studies have reported an incidence rate among military recruits of $5-7 \%$ during boot camp [1-3]. Top-athletes also frequently encounter stress fractures, which set them back significantly in their training efforts. In female athletes stress fractures have been intimately associated with the "female athletic triad" (low energy intake, hypothalamic amenorrhea and osteoporosis)
[1]. In these populations the symptoms usually subside within weeks after immobilization of the extremity in question, but the risk of a new fracture is increased. Stress fractures affecting the tibia and feet of postmenopausal women constitute a significant problem, as prolonged non-union is often seen, resulting in longstanding disability. Usually such cases have to undergo bone-grafting operations with subsequent lengthy rehabilitation and continued disability.

The pathogenesis and the natural history of stress fractures are still poorly elucidated. The predominant hypothesis focuses on increased mechanical strain placed on the lower extremity 
causing mechanical fatigue damage of bone, microcrack accumulation and ultimately clinical fracture are the primary factors invoked $[1,3,4]$. Healing of stress fractures is different from that of classical osteoporotic fractures. While classical clinical fractures heal via endochondral ossification, with an initial inflammatory response and the formation of a cartilage callus [6] stress fractures heal by normal bone remodeling, with osteoblasts rebridging broken cortices and trabeculae [7]. Because remodeling activity is much higher in cancellous than cortical bone, the development of most stress fractures begins in cortical bone.

Inherent to any injury to bone, microcracks included, is the formation of Bone Marrow Lesions (BMLs) or Bone Marrow Edema (BME). We have chosen to use the term BML instead of BME, because no edema has been demonstrated on ultrastructural examination of these lesions [8]. All stress fractures exhibit BMLs with and without fracture lines on $\mathrm{X}$-ray or CT, and in cases of delayed union these lesions persist. The development of BMLs is thought to take place before clinical fractures occur [1], therefore they are detected with and without fracture lines on MRI. Albeit poorly defined at the tissue level, there is increasing evidence including studies from our groups, that BMLs constitute a localized area of high turnover and vascularity [9]. It is therefore conceivable that the formation of a BML in some cases could interfere with healing due to the high remodeling activity and the increased osteoclastic activity accompanying a high turnover state.

Bisphosphonates have been shown to reduce or remove BMLs. This was first demonstrated in transient osteoporosis of the hip [10], but also in relation to bone bruises and osteoarthritis [11]. Both oral and iv. Bisphosphonates have been tested in the treatment of BMLs, with iv. Bisphosphonates being more effective $[10,11]$. The aim of this study was therefore to test whether intravenous dosing of a potent bisphosphonate (zoledronic acid) might promote healing of complicated stress fractures exhibiting delayed healing (> 12 months with persisting pain at fracture site). Due to previous studies showing higher doses of bisphosphonates being more effective in other conditions characterized by BML formation such as transient osteoporosis [12] or OA [13], we chose to double the dose by giving 2 infusions of zoledronic acid ( $5 \mathrm{mg}$ ) within a 3 month interval.

\section{Materials and methods}

Seven females and one male with non-healing stress fractures (aged 30-72) were enrolled. Inclusion was based on the presence of more than 12 months of non-healing, as reflected in unchanged pain, disability and persistent BMLs on MRI in the area affected (Table 1). Exclusion criteria were the following: 1) presence of metabolic bone disease or other diseases casing secondary osteoporosis; 2) poor oral status associated with increased risk of osteonecrosis of the jaw; 3) previous subtrochanteric femoral fracture. 5 patients suffered 1-3 metatarsal fractures, 2 of the cuboid bone and 1 of the calcaneus (Table 1). The duration of non-healing varied between 12 and 36 months. None of the patients were using non-steroid anti-inflammatory drugs (NSADS) or glucocorticoids known to affect fracture healing. None of the patients had undergone previous treatment with bone active drugs (HRT, bisphosphonates, denosumab, teriparatide). Stress fractures were verified by the presence of BMLs, with or without fracture lines on MR in the area of maximal pain on examination (Figure 1).

The project and dosing regimen was approved by the regioneal ethical committee (REK 2014/1986-8) and the Norwegian Medicines agency (SLV NO2014-003418-27). After informed consent, the patients were subjected to a general workup for osteoporosis and other skeletal diseases including DXA of the spine and hip, assessment of general calcium metabolic status and bone turnover markers. Subsequently they were given 2 intravenous infusions of Aclasta $5 \mathrm{mg}, 3$ months apart. Pain was monitored using visual analog scale (1-10) at baseline and 3,6 and 12 months after initiations of treatment. MRI was performed in six of the patients at baseline and 12 months after the first infusion. All patients received 0.5-1 $\mathrm{g}$ Ca and vitamin D supplementation was given in order reach S-25(OH)D levels between 75 and $125 \mathrm{nmol} / \mathrm{l}$.

\section{Statistical analysis}

Changes in VAS scores were analyzed using one-way ANOVA.

Table 1: Duration: duration of non-healing.

\begin{tabular}{|c|c|c|c|c|c|c|c|c|}
\hline Pas. & Age & Duration & VASO & VAS3 & VAS6 & VAS12 & BML12 & Location \\
\hline 1 & 62 & $24 \mathrm{mo}$ & 8 & 2 & 0 & 0 & Absent & Metatarsal 5 \\
\hline 2 & 60 & $18 \mathrm{mo}$ & 8 & 0 & 0 & 0 & Reduced & Metatarsal 1,3 \\
\hline 3 & 51 & $12 \mathrm{mo}$ & 7 & 3 & 3 & 2 & Reduced & Cuboid \\
\hline 4 & 30 & $36 \mathrm{mo}$ & 7 & 0 & 0 & 0 & NA & Metatarsal 3,4,5 \\
\hline 5 & 60 & $24 \mathrm{mo}$ & 5 & 2 & 1 & 1 & NA & Metatarsal 3,4 \\
\hline 6 & 63 & $36 \mathrm{mo}$ & 8 & 3 & 1 & 1 & Reduced & Metatarsal 4,5 \\
\hline 7 & 72 & $18 \mathrm{mo}$ & 7 & 3 & 1 & 0 & Reduced & Calcaneus \\
\hline 8 & 52 & $12 \mathrm{mo}$ & 8 & 3 & 3 & 3 & Reduced & Cuboid \\
\hline 9 & 55 & $12 \mathrm{mn}$ & 7 & 0 & 0 & 0 & Absent & Metatarsal 1-5 \\
\hline Mean & & & 7.3 & 2.0 & 1,1 & 0.9 & & \\
\hline
\end{tabular}

VAS $0,3,6,12$ : VAS registration at baseline, 3,6 and 12 months; BML12: size of bone marrow lesion at 12 months compared to baseline; NA: Not Available

Citation: Fink-Eriksen E, lanssen T, Husebye EE (2021) IV. Bisphosphonates promote healing of complicated stress fractures in the foot. Open J Orthop Rheumato 


\section{Results}

Baseline characteristics of the patients enrolled are given in Table 1. All patients experienced clinical healing defined as significant reduction of - or no pain at weight bearing 12 months. VAS scores were reduced from an average of 7.3 before treatment to 0.9 at 6 months and 0,7 at 12 months (ANOVA $\mathrm{p}<0.0001)$ post first infusion. The vast majority of patients experienced VAS pain scores ranging from 7 to 8 , with one patient recording a VAS score of 5 prior to treatment (Figure 2). All patients experienced significant pain reduction after 3 months, with further improvement in 7 of 9 patients at 6 and 12 months. Six of nine patients were pain free at 12 months, while 3 experienced residual pain with VAS scores ranging from 1 to 3. No patient experienced a new stress fracture after the first dose, but the second infusion resulted in further reduction of pain and improved mobility in 4 patients (Figure 2 ). Significant improvement was seen after 1-3 months and at self-evaluation at 6 months ambulatory function was completely restored in all patients. The reduction in pain persisted for 12 and even 24 months in all 6 patients where long term follow-up was possible. The alleviation of pain was accompanied by reduction or total resolution of the BMLs on MRI.

No severe side effects to bisphosphonate treatment were registered except for mild acute phase reactions, with fever, arthralgias and muscle pains after the first infusion in 2 patients. No patients refused the second infusion.

\section{Discussion}

The results obtained in this study suggest, that the iv. Bisphosphonate zoledronic acid promotes healing of stress fractures exhibiting delayed healing despite conventional

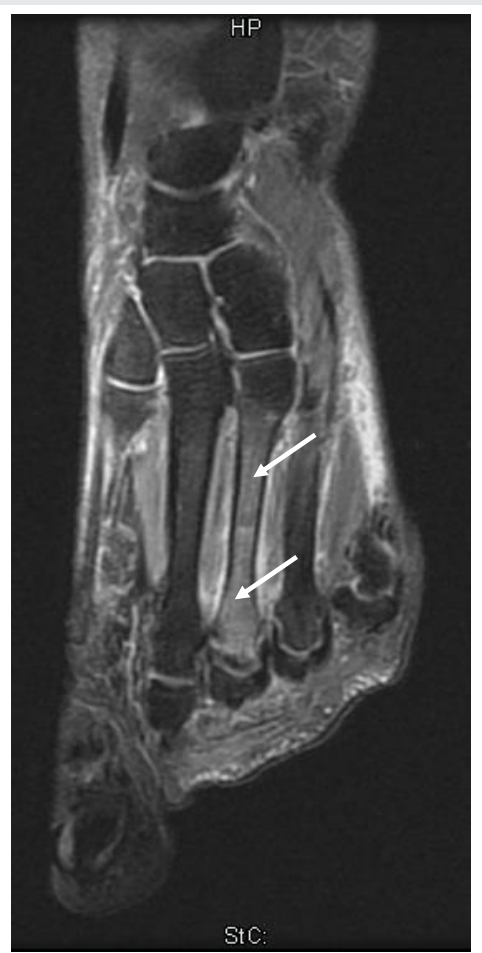

Figure 1: MRI of stress fracture in third metatarsal with extensive bone marrow edema (arrows) and visible fracture line.

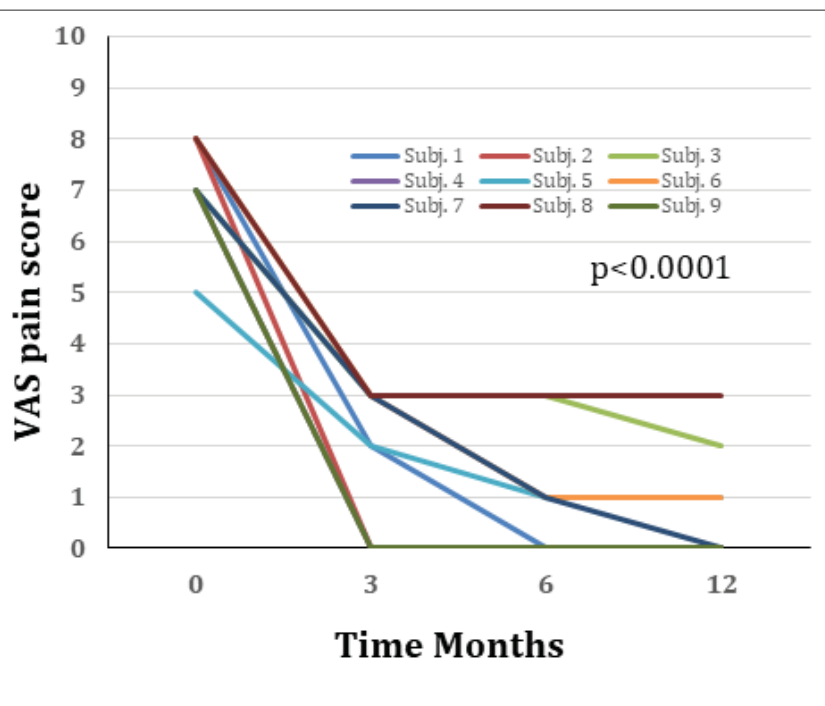

Figure 2: Individual VAS pain scores at fracture site at baseline (0) and 3,6 and 12 months after the first iv. dose of Zoledronic acid $(5 \mathrm{mg})$. Second dose was given at 3 months. No further dosing at 6 and 12 months.

treatment (crutches or casts to achieve non-weight bearing). The usual healing time for stress fractures using conventional treatment is 2 maximally 3 months. We therefore chose extreme cases with non-healing lasting more than 12 months. It is also worth noticing that the majority of cases had more than one fracture (range 2-5), which emphasizes the severity of disesae treated, BMLs have been demonstrated in association with all fractures of the axial or peripheral skeleton $[8,14]$. The main differential diagnoses to BMLs, are osteonecrosis, infection and neoplastic diseases [8]. These diseases were ruled out by our basic workup of patients in this study. The pathologies underlying formation of BMLs are still poorly defined. Very few histological studies on BMLs have been performed, but the available data suggest that the lesion is characterized by fibrosis, lymphocytic infiltrates, haemorrhage, myxomatous degeneration, increased marrow adiposity and increased vascularisation. Using dynamic fluorescence microscopy and histomorphometry analysis of BMLs from hip OA patients our group recently demonstrated that BMLs are characterized by extreme high turnover, - 25 times higher and 10 fold higher vascular area than surrounding bone without BML [9]. It is probably the latter which $\mathrm{s}$ responsible for the water signal seen on MR, because no edema by histological criteria has been demonstrated in BMLs $[15,16]$. The presence of vital trabeculae covered by osteoblasts and osteoid seams, distinguish this condition from osteonecrosis. Samples obtained from bone marrow surrounding BMLs reveal elevated levels of markers of bone turnover indicating localized high turnover [17]. This characterization has been further supported by histopathological findings from the affected areas. Other studies have demonstrated increased expression of proangiogenic factors like VEGF, CYR61, and CTGF. The authors postulated that the high expression of VEGF and CYR61 in the lesion could be caused by hypoxia, indicating a role of these proteins in the repair processes on-going in osteonecrosis [18]. However, the increased levels could also be a consequence of increased bone turnover and vascularization, which would fit the increased levels of bone markers demonstrated in BMLs

Citation: Fink-Eriksen E, lanssen T, Husebye EE (2021) IV. Bisphosphonates promote healing of complicated stress fractures in the foot. Open J Orthop Rheumato 6(1): 057-061. DOI: https://dx.doi.org/10.17352/ojor.000039 
[17]. Another study reported positive immunoreactivity for TNF-alpha, IL-6, RANKL, OPG, and OPN in bone marrow and bone of RA patients.[17]. Increased levels of these factors could explain the increased resorption in the area, as proinflammatory cytokines stimulate osteoclast activity. It is conceivable that some patients develop localized hyperresorption inside the BML surrounding the fracture. This might prevent rebridging of trabeculae by osteoblastic bone formation, which is key to healing. The positive effect of bisphosphonates could be that they by inhibiting bone resorption might let osteoblastic bone formation dominate and complete the rebridging process. Thus, histological and biochemical marker profiles, summarized above, indicate that BMLs constitute a local area of high bone turnover, increased vascularization and increased expression of cytokines and angiogenic factors.

Bisphosphonates in general exert anti-osteoclastic action by eliciting osteoclast apoptosis [19]. After oral or parenteral administration bisphosphonates are deposited on bone surfaces and subsequently incorporated into osteoclasts during bone resorption. Intracellularly bisphosphonates inhibit a crucial enzyme of the mevalonate pathway, farnesyl pyrophosphate synthase (FPPS)., which blocks the biosynthesis of isoprenoid compounds. These compounds are essential for the posttranslational modification of small guanosine triphosphate (GTP)-binding proteins securing anchoring of these protein in the phospholipid bilayer of the cell membrane. Absence of these modifications results in disorderly organization of these proteins throughout the cell causing osteoclast apotosis [19].

Zoledronic acid, however, has another significant effect, which is distinct from promoting osteoclast apoptosis. It exerts strong anti- angiogenic activity [20], which is the way by which the drug is thought to reduce BMLs [21] and promote healing. In our recent histology study on BMLs from OA patients we found a 10 fold increase in vascularity [9]. Angiogenesis is an integral part of fracture healing, but in case of BML formation maybe excessive angiogenesis inside the BML lesion may inhibit trabecular and cortical rebridging. Bisphosphonates have been shown to reduce BML size in conditions like osteoarthritis and rheumatoid arthritis. Our histology data would suggest that the water signal associated with BMLs on MR is due to increased vascularity. Thus, the reduction of BML size is probably mainly caused by anti-angiogenesis reducing blood flow in the area.

Zoledronic acid may also have improved bone healing by other mechanisms. Bisphosphonates improve bone material properties in animal models and in humans on chronic glucocorticoid therapy $[22,23]$ and also increase callus strength [24].

One study did not study delayed healing, but examined effects of another bisphosphonate, iv. ibandronate, in 25 athletes with either demonstrable BML or stress fracture on MR. The drug caused reduction of pain at rest and under strain along with improved mobility in 16 of 25 athletes within 2 weeks. Furthermore, in subjects with early onset of treatment, the time needed before returning to activities was shortened [25]. Intravenous pamidronate was reported to be effective in reducing the time needed before returning to training after stress fracture in a smaller study comprising 5 athletes [26]. An Israeli study of military recruits, however, was unable to demonstrate significant reduction of stress fracture incidence, onset or severity of fractures after an initial 12-week course of oral risedronate at the start of training [27]. Two studies have reported effects of bisphosphonates on stress fractures in special disease areas. One analysis found insufficient evidence for a positive effect on insufficiency fractures and avascular necrosis of the pelvis after pelvic radiotherapy for prostate cancer [28]. Another study, however, reported positive effects of bisphosphonates on stress fractures in patients suffering from Paget's disease [29].

The positive effect on healing of stress fractures demonstrated in this study is somewhat surprising in light of recent reports reporting the development of so called Atypical Femoral Fractures (AFF) in patients on long term treatment with bisphosphonates. Although the pathogenesis underlying AFFs is poorly defined, the pathogenesis is considered to be similar to that of stress fractures [7]. These very rare fractures (risk 1/10,000-1/100,000) usually start with a cortical defect in the lateral cortex of the subtrochanteric region, which may persist for many months before a clinical subtrochanteric fracture develops. Despite these clinical similarities, however, the pathogenesis may differ significantly. One of the differences already reported is the presence of mineralization defects in AFFs, creating a histological picture similar to that of hypophosphatasia [31]. None of the individuals participating in this study developed atypical fractures, which generally has been associated with much larger doses and longer duration of bisphosphonate treatment [7]. The fact that 2 patients developed post dose symptoms after the first infusion was to be expected as $40 \%$ of patients have been reported to develop this side effect [32]. None of the two experienced any side effects after the second infusion.

The limitations of this study are: 1) the absence of a blinded randomized design and the small sample size; 2) lack of function scores with assessment of results being confined to pain only. Obviously, the results need to be corroborated in a larger randomized blinded study. It is startling, however, that all patients with symptoms lasting more than 1 year without change experienced significant reduction of pain as assessed by VAS within weeks after the first infusion.

In conclusion, 2 infusions of zoledronic acid $(5 \mathrm{mg})$ given 3 months apart, may emerge as a possible treatment modality of stress fractures in the foot showing delayed union, and could possibly reduce the need for more extensive surgical intervention in such complicated cases. This small observational pilot study needs to be corroborated in a larger randomized, controlled trial.

\section{References}

1. McCormick F, Nwachukwu BU, Provencher MT (2012) Stress fractures in runners. Clin Sports Med 31: 291-306. Link: https://bit.ly/2VIMEi5

2. Patel DR (2010) Stress fractures: diagnosis and management in the primary care setting. Pediatr Clin North Am 57: 819-827. Link: https://bit.ly/3rdVQXr 
3. Reeder MT, Dick BH, Atkins JK, Pribis AB, Martinez JM (1996) Stress fractures Current concepts of diagnosis and treatment. Sports Med 22: 198-212. Link: https://bit.ly/36Ejwe7

4. Burr DB, Milgrom C, Boyd RD, Higgins WL, Robin G, et al. (1990) Experimenta stress fractures of the tibia. Biological and mechanical aetiology in rabbits. Bone Joint Surg Br 72: 370-375. Link: https://bit.ly/3xJOrlp

5. Lyles KW, Colon-Emeric CS, Magaziner JS, Adachi JD, Pieper CF, et al. (2007) Zoledronic Acid in Reducing Clinical Fracture and Mortality after Hip Fracture N Engl J Med 357: 1799-1809. Link: https://bit.ly/3B6z7RL

6. Colon-Emeric C, Nordsletten L, Olson S, Major N, Boonen S, et al. (2011) Association between timing of zoledronic acid infusion and hip fracture healing. Osteoporos Int 22: 2329-2336. Link: https://bit.ly/3zhRI19

7. Shane E, Burr D, Ebeling PR, Abrahamsen B, Adler RA, et al. (2010) Atypical subtrochanteric and diaphyseal femoral fractures: report of a task force of the American Society for Bone and Mineral Research. J Bone Miner Res 25: 2267 2294. Link: https://bit.ly/2UQI7Lg

8. Eriksen EF, Ringe JD (2012) Bone marrow lesions: a universal bone response to injury? Rheumatol Int 32: 575-584. Link: https://bit.ly/3erVQOm

9. Shabestari M, Vik J, Reseland JE, Eriksen EF (2016) Bone marrow lesions in hip osteoarthritis are characterized by increased bone turnover and enhanced angiogenesis. Osteoarthritis Cartilage 24: 1745-1752. Link: https://bit.ly/36ECNw5

10. Ringe JD, Dorst A, Faber H (2005) Effective and rapid treatment of painful localized transient osteoporosis (bone marrow edema) with intravenous ibandronate. Osteoporos Int 16: 2063-2068. Link: https://bit.ly/3z1Kt7M

11. Laslett LL, Dore DA, Quinn SJ, Boon P, Ryan E, et al. (2012) Zoledronic acid reduces knee pain and bone marrow lesions over 1 year: a randomised controlled trial. Ann Rheum Dis 71: 1322-1328. Link: https://bit.ly/3kn0jG3

12. Ringe JD, Body JJ (2007) A review of bone pain relief with ibandronate and other bisphosphonates in disorders of increased bone turnover. Clin Exp Rheumatol 25: 766-774. Link: https://bit.ly/36Cv0Px

13. Buckland-Wright JC, Messent EA, Bingham CO, Ward RJ, Tonkin C (2007) A 2 yr longitudinal radiographic study examining the effect of a bisphosphonate (risedronate) upon subchondral bone loss in osteoarthritic knee patients. Rheumatology (Oxford) 46: 257-264. Link: https://bit.ly/3xKUnuk

14. Voormolen $\mathrm{MH}$, van Rooij WJ, van der Graaf Y, Lohle PN, Lampmann LE, et al (2006) Bone marrow edema in osteoporotic vertebral compression fractures after percutaneous vertebroplasty and relation with clinical outcome. AJNR 27: 983-988. Link: https://bit.ly/2VINnzP

15. Kubo T, Yamamoto T, Inoue S, Horii M, Ueshima K, et al. (2000) Histological findings of bone marrow edema pattern on MRI in osteonecrosis of the femoral head. J Orthop Sci 5: 520-523. Link: https://bit.ly/3BjUTlg

16. Martig S, Boisclair J, Konar M, Spreng D, Lang J (2007) MRI characteristics and histology of bone marrow lesions in dogs with experimentally induced osteoarthritis. Vet Radiol Ultrasound 48: 105-112. Link: https://bit.ly/3BcghIO

17. Berger CE, Kroner AH, Minai-Pour MB, Ogris E, Engel A (2003) Biochemical markers of bone metabolism in bone marrow edema syndrome of the hip Bone 33: 346-351. Link: https://bit.ly/3eoWvA2
18. Radke S, Kenn W, Eulert J (2004) Transient bone marrow edema syndrome progressing to avascular necrosis of the hip - a case report and review of the literature. Clin Rheumatol 23: 83-88. Link: https://bit.ly/2UR80ya

19. Russell RG (2007) Bisphosphonates: mode of action and pharmacology. Pediatrics 119: S150-S162. Link: https://bit.ly/3BiWdVB

20. Green J, Lipton A (2010) Anticancer properties of zoledronic acid. Cancer Invest 28: 944-957. Link: https://bit.ly/3elaHdu

21. Eriksen EF (2015) Treatment of bone marrow lesions (bone marrow edema) Bonekey Rep 4: 755. Link: https://bit.ly/3wINx7]

22. Allen MR (2018) Recent Advances in Understanding Bisphosphonate Effects on Bone Mechanical Properties. Curr Osteoporos Rep 16: 198-204. Link: https://bit.ly/3wJf7RR

23. Mellibovsky L, Prieto-Alhambra D, Mellibovsky F, Guerri-Fernandez R, Nogues X, et al. (2015) Bone Tissue Properties Measurement by Reference Point Indentation in Glucocorticoid-Induced Osteoporosis. J Bone Miner Res 30 1651-1656. Link: https://bit.ly/3ekjoF1

24. Hao Y, Wang X, Wang L, Lu Y, Mao Z, et al. (2015) Zoledronic acid suppresses callus remodeling but enhances callus strength in an osteoporotic rat model of fracture healing. Bone 81: 702-711. Link: https://bit.ly/3i9CbE4

25. Simon MJ, Barvencik F, Luttke M, Amling M, Mueller-Wohlfahrt HW, et al (2014) Intravenous bisphosphonates and vitamin D in the treatment of bone marrow oedema in professional athletes. Injury 45: 981-987. Link: https://bit.ly/3rcdTgT

26. Stewart GW, Brunet ME, Manning MR, Davis FA (2005) Treatment of stress fractures in athletes with intravenous pamidronate. Clin J Sport Med 15: 92 94. Link: https://bit.ly/2VFan2

27. Finestone A, Milgrom C (2008) How stress fracture incidence was lowered in the Israeli army: a 25-yr struggle. Med Sci Sports Exerc 40: S623-629. Link: https://bit.ly/3wMgY8t

28. van den Blink QU, Garcez K, Henson CC, Davidson SE, Higham CE (2018) Pharmacological interventions for the prevention of insufficiency fractures and avascular necrosis associated with pelvic radiotherapy in adults. Cochrane Database Syst Rev 4: CD010604. Link: https://bit.ly/2VIOpfb

29. Kumar R, Selviambigapathy JK, Kamalanathan S, Sahoo JP (2017) Stress fractures healing with bisphosphonates in Paget's disease. Joint Bone Spine 84: 91. Link: https://bit.ly/3wNT5gB

30. Shabestari ME, Eriksen EF, Roschger P, Paschalis E, Diez-Perez A (2012) A Case of Atypical Femoral Fracture with Abnormal Cortical Bone Characterized by Impaired Mineralization and Pyrophosphate Accumulation Paper presented at the ASBMR Annual Meeting 2012, Minneapolis USA.

31. Sutton RA, Mumm S, Coburn SP, Ericson KL, Whyte MP (2012) "Atypical femora fractures" during bisphosphonate exposure in adult hypophosphatasia. J Bone Miner Res 27: 987-994. Link: https://bit.ly/3epdliB

32. Black DM, Delmas PD, Eastell R, Reid IR, Boonen S, et al. (2007) Once-yearly zoledronic acid for treatment of postmenopausal osteoporosis. N Engl J Med 356: 1809-1822. Link: https://bit.ly/36CcjeN

Copyright: (c) 2021 Fink-Eriksen E, et al. This is an open-access article distributed under the terms of the Creative Commons Attribution License, which permits unrestricted use, distribution, and reproduction in any medium, provided the original author and source are credited.

Citation: Fink-Eriksen E, lanssen T, Husebye EE (2021) IV. Bisphosphonates promote healing of complicated stress fractures in the foot. Open J Orthop Rheumatol 6(1): 057-061. DOI: https://dx.doi.org/10.17352/ojor.000039 